\title{
De usos no presente aos usos no passado: a coleta de frases como técnica de leitura e de escrita
}

DOI: http://dx.doi.org/10.21165/el.v50i3.2984

\author{
Pâmela Rosin' \\ Luzmara Curcino ${ }^{2}$
}

\section{Resumo}

Fundamentadas por princípios da Análise do discurso e da História Cultural da leitura, e interessadas nos discursos sobre a leitura, no que em geral se diz sobre essa prática, neste artigo, apresentamos um breve panorama histórico de uma técnica de leitura e de escrita de longa-duração, que consiste na leitura, seleção, destacamento, coleção e emprego dessas frases em outros textos. Na atualidade, multiplicam-se gêneros próprios da cultura digital que se valem dessa técnica e que se apresentam como o resultado da articulação de fragmentos de textos verbais, de imagens, de sons. Das "mensagens em powerpoint", passando pelas "mensagens compartilhadas" aos "memes", somos testemunhas dessa cultura do fragmento que tem uma história, que se inscreve em uma memória e que tem impacto sobre o modo como hoje lemos e escrevemos nossos textos. É esse breve panorama que aqui apresentamos.

Palavras-chave: história da leitura; técnica de leitura e de escrita; frases destacadas; cultura digital, cultura do fragmento.

1 Universidade Federal de São Carlos (UFSCar), São Carlos, São Paulo, Brasil; pamelasilvarosin@gmail.com; https://orcid.org/0000-0002-7778-8874

2 Universidade Federal de São Carlos (UFSCar), São Carlos, São Paulo, Brasil; luzcf@ufscar.br; https://orcid.org/0000-0003-3555-1446 


\title{
From uses in present to uses in past: note-taking as a reading and writing technique
}

\begin{abstract}
Grounded by Discourse Analysis and Cultural History of reading principles, and with an interest in discourses about reading, on what is generally said about such practice, in this paper we present a brief historical panorama of a long-term reading and writing technique, which consists in reading, selection, detachment, collection and employment of such phrases in other texts. Nowadays, digital culture's genres that use this technique multiply, presenting themselves as the result of the articulations of fragments from verbal texts, images, and sounds. From "PowerPoint messages" to "shared messages" to "memes", we are witnesses to this culture of the fragment that has a history inscribed in memory and has an impact on the way we read and write our own texts today. It is this brief panorama that we presented here.
\end{abstract}

Keywords: history of reading; reading and writing technique; detachability; digital culture, culture of the fragment.

\section{Fragmentos, frases, citações: das telas ao rolo}

O desenvolvimento contemporâneo e acelerado de Tecnologias da Informação e Comunicação (TICS) proporcionou uma mudança em uma série de produtos culturais destinados à produção e à circulação de informações, bem como de meios de interlocução inusitados, com a multiplicação de plataformas on-line ${ }^{3}$. Esse desenvolvimento também foi responsável, até certo ponto, pela variação de várias de nossas práticas cotidianas. Muitos de nós já despende, diariamente, consideráveis horas frente à tela de dispositivos eletrônicos, como computadores, smartphones, tablets e outros. Entre as práticas cotidianas, sem dúvida alguma, os modos como lemos e nos valemos da escrita foram sensivelmente afetados, comparativamente àqueles de que nos valíamos na cultura impressa.

Se antes grande parte dos textos com que lidávamos no nosso dia a dia apresentavamse prioritariamente em suportes impressos como livros, jornais e revistas, mas também folhetos, cartazes, outdoors, na contemporaneidade, sua circulação é também garantida por plataformas digitais cujo acesso é possibilitado por diferentes softwares e hardwares e mediado por outras instituições, distintas daquelas mais tradicionais com que estávamos

3 Com o advento da Web 2.0, altera-se o modo de interação dos usuários, uma vez que se viabiliza a troca de informações e a criação de conteúdos de modo colaborativo e em tempo real. Dentre os recursos possibilitados pela sua invenção, destacamos a criação de sites, blogs, microblogs, wikis, redes sociais etc. 
mais familiarizados ${ }^{4}$. Alguns de nós dispõem de vários dispositivos eletrônicos, cada vez mais conectados, e que nos mantêm todo o tempo on-line. Diferentemente de outras revoluções históricas outrora assim identificadas quanto à escrita e à leitura de textos, estamos vivenciando, como afirma o historiador Roger Chartier (1999), uma revolução de fato, e sem precedentes, das formas de comunicação, de produção e de circulação dos textos, bem como de seu acesso, uma vez que a atual revolução técnica, tecnológica e de usos conjuga mudanças de diferentes ordens: quanto ao suporte, quanto às técnicas de escrita, edição e transmissão, quanto às formas de recepção dos textos.

\section{Do manuscrito ao impresso: uma revolução?}

Embora se tenha aventado o mesmo em relação à invenção dos tipos móveis de Gutenberg, no século XV55 , segundo Chartier (1999), esta invenção, no limiar da Idade Média e advento do Renascimento, foi equivocadamente designada como "revolução". Ainda que esta tenha sido uma invenção técnica de grande envergadura e impacto, em especial no que diz respeito à história da sociedade Ocidental, ela não significou uma mudança efetiva da forma, ou seja, da materialidade dos objetos culturais portadores da escrita, como o "livro" ou os panfletos, até então manuscritos. Também por isso ela não significou uma mudança na forma de apropriação desses objetos, nos modos de sua leitura.

Se se pode falar em "revolução" de Gutenberg, ela diz respeito (e isso não é, de modo algum, pouca coisa) à expansão sem precedentes da escala de produção e de reprodução dos textos, logo da viabilização de seu acesso, efetivo e potencial, para um público progressivamente mais amplo e diverso.

Para o historiador, com a invenção dos tipos móveis, conjugados ao uso da prensa, não houve, portanto, uma mudança ou desestabilização da forma de apresentação, de organização e de estruturação dos textos, e de seus suportes tradicionais, nem do seu manejo e uso, ou seja, dos modos de se ler. Conforme o autor, se houve revolução isso não se deu da mesma forma como ocorrera 13 séculos antes quando da invenção do

4 Desde as bibliotecas físicas até as empresas tradicionais de informação e comunicação impressa ou televisiva, passando pelas gráficas, editoras e livrarias, é todo um conjunto amplo de instituições que compartilham espaço hoje com a cultura de materialidade digital, acessível por telas diversas.

5 Cf., a esse respeito, o livro de Elizabeth Eisenstein, intitulado A revolução da cultura impressa: os primórdios da Europa Moderna, publicado em 1979 e traduzido para o português em 1998, no qual desde o título afirma-se o caráter "revolucionário" da invenção dos tipos móveis, da invenção que no Ocidente é atribuída a Gutenberg. Outro exemplo, é o livro intitulado A Revolução de Gutenberg: a história de um gênio e da invenção que mudou o mundo, de John Man, publicado em 2003, e traduzido logo em seguida para o português. O subtítulo não deixa dúvidas quanto ao caráter entusiasmado de reconhecimento dessa 'revolução'. 
códice, ou seja, da forma do livro como a conhecemos ainda hoje: como um conjunto de folhas planas (antes de madeira com cera, algumas de metal, mas a grande maioria de pergaminho ao longo de toda Idade Média, até a descoberta e a consagração do papel), de que se pode usar sua frente e verso, reunidas em bloco, amarradas ou costuradas, e progressivamente encadernadas ${ }^{6}$.

Com a passagem do rolo ou volumen - principal objeto de inscrição de textos ao longo da Antiguidade grega e romana - para o formato do códice - que emerge entre os séculos II e IV7, e que progressivamente substitui o objeto anterior, se testemunha uma "revolução", a justo título, na história do livro e da leitura. Essa mudança de um suporte de inscrição textual para outro implicou alterações significativas nos modos de ler e de escrever. Por exemplo, com a liberação das mãos durante a leitura - não mais exigidas para segurar e manter aberto o rolo, e cujo texto então no formato do códice, com suas folhas planas, ainda que em grandes formatos, podia ser folheado, uma vez disposto sobre uma mesa ou outro móvel -, foi possível ao leitor realizar anotações à medida que lia, ou seja, fazer notas marginais no próprio texto, simultaneamente à sua leitura, ou em outro objeto destinado para essas notas. Essa forma nova do texto e as possibilidades de seu folheamento agilizaram aquelas leituras feitas com a finalidade de produzir outros textos, especialmente aquelas empreendidas no trabalho intelectual de escrita de novos textos.

Não era mais preciso, como antes, saber o texto de cor, para fazer posteriores citações de seu conteúdo. O novo formato do livro não apenas liberou as mãos do leitor, e com ela a possibilidade de realizar anotações concomitantes de passagens dos textos lidos, como também propiciou a criação de sistemas técnicos mais práticos de recuperação das informações textuais (como a paginação, a indexação das partes e a paragrafação), ampliando a capacidade e a agilidade de identificação de informações presentes nos textos lidos, sobretudo os mais extensos, e que serviriam de subsídios para a produção de novos textos. Com a nova materialidade dos textos, sob a forma do códice, ou seja, do livro tal como o conhecemos ainda hoje - de folhas reunidas, encadernadas, paginadas, sumarizadas -, não apenas se criou um sistema mais eficiente de retomadas e de localização de trechos selecionados, com vistas a sua mais fácil citação em outros textos, como também se permitiu um aproveitamento maior dos materiais de escrita, dado que com esse formato das folhas se poderia escrever de ambos os lados, frente e verso, em cada página.

Os textos podem, nesse novo formato, ser mais extensos, sem com isso se acrescentar uma maior lentidão ou dificuldade de sua leitura e de sua posterior consulta pontual.

6 Para informações gerais sobre aspectos materiais do livro, de sua forma do rolo ao códice, cf. o site http://www.escritoriodolivro.com.br/.

7 Cf., a esse respeito, Roger Chartier (2002). 
Embora maiores, eles se apresentam de forma mais amigável ao olhar do leitor, porque sua textualidade passa a contar com índices facilitadores de identificação e de recuperação de certas passagens, com o emprego mais sistematizado de sinais gráficos de separação de partes e de formas que atuavam como uma versão do que viria a ser a nossa pontuação hoje em dia.

Entre os diversos índices que vão sendo introduzidos no layout de apresentação dos textos, divididos em páginas e, no interior dela, em blocos (do que viriam a ser os capítulos, os itens, os subitens, os parágrafos, as frases, as palavras), a ampliação dos "brancos" no texto foi fundamental nesse processo. Empregados desde o século XI, nos textos manuscritos $^{8}$, essa foi a principal modificação nos textos impressos, observável entre os séculos XVI e XVIII, e decisiva na:

[...] aeração da página pela multiplicação dos parágrafos que quebram a continuidade ininterrupta do texto, e aquela das alíneas, que entre idas e vindas à linha tornam a ordem do discurso imediatamente mais legível. Uma nova leitura das mesmas obras ou dos mesmos gêneros é assim sugerida pelos editores de então; uma leitura que fragmenta os textos em unidades separadas, e que reencontra, na articulação visual da página, as conexões intelectuais ou discursivas do raciocínio. (CHARTIER, 1999, p. 18-19).

Esses índices se sofisticaram progressivamente, ampliando as pausas do olhar leitor sobre o texto, cada vez mais "aerado", dividido em menores porções, o que autorizava e estimulava a possibilidade de suspensão temporária da leitura do texto, assim como viabilizava sua mais simples retomada, e tudo isso graças a essas subdivisões tanto editoriais do gênero discursivo, ou estéticas, quanto semânticas e intelectuais, incorporadas a sua apresentação9 .

A mudança de função da prensa tradicional combinada com a invenção dos tipos móveis de Gutenberg, que inauguraria a era do impresso, como afirma Chartier (1999), foi a herdeira dessa "revolução" de longa data, lenta e progressiva, assim como menos

8 Entre outros autores que abordaram historicamente esse aspecto da "inserção dos brancos" nos textos e de seu impacto sobre a leitura, cf. Paul Saenger (1998), que observa as formas sofisticadas já empregadas na cultura manuscrita de definição da separação das palavras, facilitando com isso a leitura em silêncio, apenas com os olhos.

9 Esse processo de aeração dos textos, de inclusão de subdivisões, de sua intercalação com imagens se acentuou graças a uma série de tecnologias, e se intensificou especialmente em alguns gêneros, ao longo do tempo. Nossa escrita na atualidade é herdeira desse processo. Nos textos da mídia (jornais e revistas) essas formas de aeração são particularmente sensíveis e vêm se expandindo sob o impacto das TIC's. A esse respeito, cf. entre outros, Curcino $(2006,2014)$ e Silva (2007). 
alardeada, que ocorreu na forma do livro: aquela que remonta a sua passagem do rolo ao códice.

A invenção de Gutenberg, embora não tenha produzido a alegada e comemorada "revolução" na produção do livro e demais objetos da cultura escrita, ou ainda nos modos de ler, nem por isso deixou de ser decisiva na agilização do processo de reprodução dos textos, contribuindo a médio e longo prazo, em grande medida, com sua democratização. Embora ela não tenha afetado direta e prontamente a forma dos objetos da cultura escrita e seus modos de ler, ela gestou mudanças em nada negligenciáveis nos livros.

Uma delas diz respeito ao surgimento do "livro unitário", no final da Idade Média, entre os séculos XIV e XV, ou seja, as "obras de um autor eram mais comumente reunidas num livro impresso do que num manuscrito" (CHARTIER, 2014, p. 113). Ainda que os leitores, antes da imprensa, já se encarregassem dessa tarefa de reunir e encadernar diferentes textos manuscritos de um mesmo autor em um único objeto, estabelecendo uma relação que hoje nos é evidente e banal, entre um objeto, o "livro", com diferentes textos de uma "obra", reunidos em função de terem sido escritos por um mesmo "autor", não era a forma mais corrente do livro ao longo da Idade Média. Isso ocorria, antes da imprensa, em uma escala bem menor, do que aquela adotada pelos livreiros-editores após a invenção de Gutenberg. Antes, como constata o historiador Roger Chartier (2014, p. 113-144), "a tradição dominante da era do manuscrito [...] era a miscelânea, combinando textos de gêneros, datas e autores bem diferentes".

Assim, as mudanças que se pode atribuir a esta invenção de Gutenberg quanto ao livro ou quanto ao modo de sua leitura devem ser nuançadas, uma vez que os leitores dos códices manuscritos, diante dos códices impressos, não estavam diante de um objeto desconhecido que thes exigisse ou lhes proporcionasse outras experiências de leitura ou outras formas de se relacionar com esse objeto portador da escrita.

Além disso, o livro impresso vai conservar, por muito tempo, uma relação de proximidade, de similitude com o livro manuscrito. Por isso, nas primeiras décadas de sua produção, o códice impresso será antes um objeto misto, resultante de práticas tanto da impressão quanto da manuscritura:

Por um lado, o livro impresso mantém-se fortemente dependente do manuscrito até por volta de 1530, imitando-lhe a paginação, as escrituras, as aparências e, sobretudo, considerando-se que ele deve ser acabado à mão: pela mão do iluminador que pinta iniciais com ornamentos ou miniaturas; a mão do corretor ou ementador, que acrescenta sinais de pontuação, rubricas e títulos; a mão do leitor que inscreve sobre a página, notas e indicações marginais. Por outro lado - e mais fundamentalmente -, tanto antes quanto depois de Gutenberg, o livro é um objeto composto por folhas dobradas, reunidas em cadernos colados uns aos outros. (CHARTIER, 1999, p. 96). 
Os primeiros textos impressos eram então corrigidos e ilustrados manualmente, seja pelos produtores do livro, seja pelos leitores que os adquiriam. Esses primeiros livros impressos, conhecidos como "incunábulos", resultam desse processo misto e lento de mudança das formas de produção e de reprodução dos textos, antigamente copiados à mão, para posteriormente serem produzidos na forma impressa, que progressivamente substitui a produção e a reprodução manuscritas.

Houve, sem dúvida, uma abertura na escala de reprodução dos impressos, em nada negligenciável e relativamente acelerada, à medida que essas intervenções que se mantiveram à mão por algumas décadas foram elas também sendo incorporadas pela técnica do impresso.

\section{Do impresso ao digital: uma revolução!}

Tal como analisado em Rosin e Curcino (2015), se a invenção da prensa e dos tipos móveis não correspondeu a uma mutação efetiva do livro, em sua forma material, o mesmo não se deu em relação à leitura, a formas segundo as quais os leitores se apropriavam e manuseavam esse objeto e os textos, o mesmo não se pode dizer do processo atual em curso, a saber, o da produção, difusão e recepção eletrônica dos textos. Esta última não altera somente a técnica de reprodução e multiplicação dos textos. Ela também modifica suas estruturas, proporcionando assim uma transformação "mais radical, pois são os modos de organização, de estruturação de consulta ao suporte do escrito que se modificaram" (CHARTIER, 1999, p. 98).

O que testemunhamos hoje, segundo o historiador, pode de fato ser chamado de "revolução", de uma revolução eletrônica, digital, virtual. Ela altera o processo de produção e reprodução dos textos, expande os seus agentes, muda as formas de circulação e de recepção desses textos, impõe novas atitudes de quem escreve e de quem lê textos por meio das telas de diferentes dispositivos, e que é bombardeado por uma proliferação contundente de textos que chegam às mãos de forma ininterrupta e em uma relativa indistinção quanto a suas origens.

Conforme observara Roger Chartier (1999, p. 100-101), há 20 anos:

[...] a revolução do texto eletrônico será, ela também, uma revolução da leitura. Ler num monitor não é o mesmo que ler num códice. Se é verdade que abre possibilidades novas e imensas, a representação eletrônica dos textos modifica totalmente a condição destes: à materialidade do livro, ela substitui a imaterialidade de textos sem lugar próprio; às relações de contiguidade estabelecidas no objeto impresso, ela opõe a livre composição de fragmentos indefinidamente manipuláveis; à apreensão imediata da totalidade da obra, viabilizada pelo objeto que a contém, ela faz suceder a navegação de muito 
longo curso, por arquipélagos textuais sem beira nem limites. Essas mutações comandam, inevitável e imperativamente, novas maneiras de ler, novas relações com o escrito, novas técnicas intelectuais.

Os leitores se encontram, no atual cenário que vem se desenhando aceleradamente nas últimas décadas, diante de "textos sem lugar próprio", cuja materialidade se adéqua ao formato e tamanho da tela a partir da qual eles são então acessados, sem que se tenha acesso imediato a sua extensão, sem que seus formatos tradicionais, de origem, sejam prontamente reconhecidos pelos leitores e sem que as regras e tradições de sua apropriação sejam conhecidas ou correspondidas ${ }^{10}$.

Embora hoje testemunhemos a criação de uma série de índices capazes de restituir algumas das distinções institucionais e de gêneros editoriais e discursivos aos textos, que no início dessa emergência do virtual foram relativamente suspensas ou embaralhadas, pela perda de seus layouts originais e por seu acesso comum via "tela" em uma materialidade "eletrônica" que os homogeneizava, ainda assim, nos encontramos diante de um longo caminho a ser percorrido na restituição/clareza das formas de distinção dos textos, de seus autores, de reestruturação de suas instâncias formais de validação, assim como da democratização do letramento digital dos leitores, de modo a lhes permitir, a todos igualmente, ter acesso de forma esclarecida e crítica aos textos que "se convidam", que se "impõem" ao nosso olhar cotidianamente, nessas máquinas de produção e de circulação de textos, às quais cada vez mais estamos conectados e pelas quais acessamos constantemente textos orientados para o "nosso perfil", "nossos interesses" e "nossas competências" de leitura.

Deriva dessas transformações, ocasionadas pela revolução eletrônica dos textos e pelas novas tecnologias digitais de informação, a criação e a difusão de sites de redes sociais que diversificaram as formas de contato interpessoais e de produção e circulação de textos de diversas origens e linguagens, afetando por vezes seus sentidos, assim como as formas e as práticas de leitura e escrita.

Tal como ocorrera com a invenção de Gutenberg, o recente processo digital de produção, circulação e recepção de textos de diferentes origens, gêneros e finalidades expandiu o acesso de textos por essa via eletrônica, intensificou a produção de alguns gêneros, e

10 Textos originalmente destinados a um público específico, de um tempo ou de grupo cultural, cuja sobrevida e novas formas de circulação tenham ampliado o espectro de sua recepção junto a públicos não previstos, são inevitavelmente lidos com outras "chaves" interpretativas, segundo outras expectativas e competências. Para um exemplo bastante significativo deste processo, cf. Curcino (2010), e sua análise das mudanças na interpretação de textos literários, filosóficos ou religiosos quando de sua circulação sob outros meios, suportes e gêneros e quando de sua recepção por um público mais amplo e variado. 
fez com que, progressivamente, diferentes grupos da sociedade, alguns destes pouco familiarizados com a leitura de certos textos ${ }^{11}$, travassem contato mais frequente com eles ${ }^{12}$.

Entre esses "novos" gêneros, vimos a aparente emergência e sua significativa difusão da prática de seleção de frases e de sua divulgação em repositórios digitais dedicados exclusivamente a isso, com os seus equivalentes em livros destinados à publicação de certas coleções de frases ${ }^{13}$. Sua novidade, no entanto, se encontra nos usos e nos procedimentos de sua coleta e disponibilização, e não propriamente na técnica de leitura e de escrita que implicam e da qual derivam.

\title{
A técnica de seleção e coleção de frases: duração e variação na história e na cultura
}

Entre as várias práticas de leitura e de escrita que se inscrevem na longa duração e que, em certa medida, se singularizam em suas atualizações, variações, em sua condição

\begin{abstract}
11 Tal como observado por Curcino (2021, p. 108), uma grande parcela da população brasileira, usuária recente da internet e de aplicativos de difusão de textos, foi sistematicamente bombardeada por vários tipos de textos, em grande medida sob a forma de notas ou de frases curtas digitadas, como se fossem "notícias" fiáveis, formulados de forma incisiva, simplista, "sem filtros", muitos deles falseadores da realidade, e que mascaravam sua inverdade. Segundo a autora, "Notícias falsas circulavam junto a verdadeiras pelo mesmo meio e com o mesmo formato. Misturadas, tudo podia ser mentira, tudo podia ser verdade, ou todas aquelas mentiras poderiam ter ao menos um fundo de verdade. Notícias verdadeiras com grande potencial polêmico e de esclarecimento eram rapidamente 'neutralizadas', seus efeitos enfraquecidos junto à opinião pública em função da concorrência com notícias falsas, mais escandalosas e impressionantes, mais 'provocadoras' e pregnantes, e em grande volume, fagocitando assim a notícia verdadeira. É nesse fluxo incessante de dizeres que se gesta sua indistinção, e com ela uma espécie de cansaço que acomoda e normaliza esse fluxo, e também de indiferença quanto ao seu valor de verdade por parte de seu destinatário".

12 São emblemáticos a expansão e o uso recente por parte de um número crescente de usuários de smartphones, de aplicativos como o WhatsApp, que se tornaram no Brasil um meio de comunicação e de produção e difusão de textos com finalidades muito distintas, usados em escala inédita e com resultados inesperados para a produção e circulação de textos com finalidades e impactos decisivos inclusive no âmbito político-eleitoral. A esse respeito cf., entre outros, Chiari e Sargentini (2019), Sargentini e Carvalho (2020) e Curcino (2019).
\end{abstract}

13 É frequente o lançamento de livros destinados à reunião de frases de autores famosos e célebres, de diversos campos do saber, particularmente do campo literário e filosófico. Destacase, em âmbito nacional, a publicação das coletâneas de frases de Clarice Lispector, pela editora Rocco, através da organização do curador Roberto Corrêa dos Santos que se dedicou a uma seleção, em grande parte, de frases oriundas das obras de Lispector, materializando-se em dois livros, As palavras (2014) e 0 tempo (2015). 
de acontecimento discursivo ${ }^{14}$, a técnica de seleção e coleção de "frases", destacadas de textos provenientes de campos diversos (religioso, filosófico, científico, mas sobretudo do campo literário), que podem vir a circular sob a forma de outros textos compostos por elas, textos de seu mesmo campo de origem, ou de campos, contextos e finalidades muito distintos de seu uso primeiro, é de uma vitalidade ímpar.

Essa técnica de seleção e coleção de "frases" se adéqua e se reinventa valendo-se de diferentes recursos inaugurados com as novas tecnologias digitais, de modo a pulular hoje em inúmeras plataformas virtuais. Algumas dessas frases se autonomizam em relação a seu texto de origem, podendo ser a base constitutiva de outros gêneros, como as "mensagens compartilhadas"15 e as "mensagens em PowerPoint"16.

Embora essa técnica se mantenha em suas linhas gerais, ao longo da história, e de um gênero contemporâneo a outro, ela é normalmente explorada de maneira diversa, com certas singularidades. Esses usos empreendidos dessas frases, que se autonomizam de seus textos e circulam sob a forma de correntes, via e-mail, ou sob a forma de mensagens nas redes sociais, por vezes no formato meme, não são os mesmos, nem têm os mesmos objetivos, nem são geradores dos mesmos efeitos de sentido daqueles empreendidos pelos antigos, pelos eruditos religiosos ou da escolástica na Idade Média, ou pelos

14 Todo enunciado, em sua produção, formulação e circulação, emerge como um acontecimento discursivo. Isso o filia, o inscreve e o submete a um já dito, anterior e específico, a uma complexa relação, segundo Foucault (2014), de repetição, refutação, transformação, denegação de outros enunciados que antes dele ou em seu entorno fazem parte das condições de sua emergência histórica e simbólica. E isso de tal modo que esse enunciado-acontecimento tanto é determinado quanto a sua atualização e aos efeitos de sua apropriação por essa "memória discursiva" e esse "campo associado" de outros enunciados, como também intervém e determina essa memória, seja reforçando a sua duração, seja alterando esse conjunto anterior do dizível sobre um tema, um sujeito ou uma prática.

15 Essas "frases" destacadas de obras e autores consagrados e que foram recortadas e passaram a circular amplamente em redes sociais, de forma independente, como um gênero específico, reconhecível em sua forma regular mista, que conjugava tanto uma citação breve de uma passagem da obra um autor quanto uma imagem que ilustrasse, decorasse e compusesse com ela esse gênero são por nós denominadas "mensagens compartilhadas". Essa denominação de "mensagens" se deve ao modo genérico como os usuários dessas redes a elas se referem, e o acréscimo desse especificador/qualificador "compartilhadas" buscou reforçar a função que exercem, por um lado, de registrar a opinião, o bom gosto, a consciência, o ponto de vista daquele que as emprega, e por outro, de atuar como forma de socialização pública, de contato, de estabelecimento e reforço de vínculos sociais. Para uma melhor descrição e exemplificação de sua forma e de seu funcionamento, conforme Rosin e Curcino (2015).

160 equivalente anterior à circulação dessas "mensagens compartilhadas" em redes sociais como o Facebook, é o das "mensagens em PowerPoint" que circularam amplamente, via e-mail, sob a forma de "correntes", tal como analisado em Curcino $(2010,2012)$. 
humanistas ao longo dos séculos XVI ao XVIII, quando aqueles que escreviam também se valiam da leitura que seleciona e da escrita que extrai fragmentos e os registra sob a forma de outros gêneros.

Embora o procedimento geral de "leitura que seleciona" e de "escrita que coleciona e que reutiliza", se assemelhe ao longo dos tempos, embora também se assemelhem os efeitos visados com a ancoragem de um texto novo em outros que lhe antecederam e aos quais já foi conferida autoridade, não se está diante dos mesmos sujeitos, dos mesmos princípios e valores culturais, dos mesmos grupos sociais, logo dos mesmos usos e das mesmas formas de validação desses usos.

Em seu artigo "Diferentes formas de ler", a pesquisadora Márcia Abreu, interessada em discutir os modos de ler contemporâneos, particularmente aqueles empreendidos em contexto brasileiro e suas representações, inicia sua discussão colocando em xeque um dos imaginários cristalizados sobre os modos de ler. Para a autora, prevalece um imaginário compartilhado de que "a leitura sempre se fizera como supomos que ela hoje se faz, em silêncio e solitariamente [...] que, em todas as épocas, ler implicava pensar sobre os textos e interpretá-los, exigindo habilidades [superiores à capacidade de] decifrar os sinais gráficos da escrita" (ABREU, 2001, s/p).

Portanto, as práticas culturais, da leitura e da escrita, na longa duração e de um grupo social a outro, têm sido valorizadas diferentemente, ora por se apostar em seu potencial moralizador e civilizador dos hábitos, ora por instruir e formar seja o cristão, seja o cidadão, seja a mulher como esposa etc., ora por favorecer o espírito crítico, ora para entreter simplesmente. Consequentemente, não são todos os modos de ler e de escrever, em um mesmo período e espaço que são valorizados do mesmo modo. As práticas que se diferenciam daquelas que em um dado tempo e cultura correspondem às formas valorizadas, de prestígio, impõem a certas variações nos modos de ler e escrever atributos depreciativos, desqualificações como "não-leitura" e "não-escrita" e que por isso podem ser, enquanto práticas exercidas por sujeitos que não fazem parte dos grupos de prestígio em uma dada sociedade, desconsideradas e invisibilizadas.

Tal como afırma a autora, na esteira de uma série de historiadores dedicados ao livro e à leitura, nem sempre se leu do mesmo modo como em nossos dias atuais, nem sempre foram validados e eleitos os mesmos tipos de leitura, nem tampouco a mobilização de um determinado modo de ler inviabilizou outro, possibilitando sua ocorrência de forma concomitante. Assim, Abreu (2001) assevera que algumas práticas, gestos e modos de leitura de hoje "[...] pareceriam disparates completos em outras épocas", por exemplo, a prática da leitura silenciosa que, para Santo Agostinho, "parecia prodigioso que se lesse com a língua quieta, pois ler em voz alta era a norma no século IV d.C." que se estendeu até o século XIV, "quando muitos nobres ainda dependiam da oralização das palavras para a compreensão de um texto" (ABREU, 2001, s/p). 
O mesmo se pode dizer da escrita. A leitura e a escrita devem ser compreendidas não como práticas homogêneas, inalteráveis, intocáveis, de maneira a ser privilegiado, fomentado e valorizado apenas um modo de ler e escrever e um único tipo de leitura e escrita ${ }^{17}$. Elas devem, antes, serem concebidas como uma pluralidade de gestos e modos que se relacionam e convivem ao longo da história e de uma cultura a outra. Gestos e modos que devemos descrever em suas regularidades e singularidades, e que devemos apreender em sua relação complexa com uma memória e uma atualidade.

Quando nos ocupamos do estudo discursivo de enunciados destacados de autores contemporâneos brasileiros e de seu compartilhamento em páginas do Facebook ${ }^{18}$, fomos levados a pensar na possibilidade de que esse destacamento e compartilhamento de "frases" de diversos campos do saber, manifestos em repositórios on-line de frases, com diferentes usos e finalidades, eram oriundos e fomentados, pelas tecnologias digitais disponíveis, ou seja, resultavam justamente dessas tecnologias. Contudo, conforme constatamos, essa prática reatualiza um fenômeno cujas origens remontam no tempo, variando ao longo da história em seus usos e formas, em sua validação, em suas apropriações particulares, o que uma dada tecnologia pode intensificar e especificar quanto a sua expansão e circulação.

\section{Da técnica na Antiguidade: selecionar, colecionar frases e empregar na escrita de novos textos}

Na Antiguidade clássica grega, por volta dos séculos I e II, essa prática de coleta de "frases" era comum entre aqueles que possuíam uma certa formação leitora, o que lhes possibilitava ler e escrever, ler para escrever ou apenas ler de um certo modo, já que a tarefa de escrita era consagrada aos escribas pessoais. Ela também era fomentada como técnica filosófica de reflexão e técnica retórica de exercício da palavra. Sua importância explica o modo prioritariamente "intensivo" com que se lia os textos e com que se valorizava a recolha e "incorporação", ou seja, a memorização de fragmentos de textos lidos ${ }^{19}$.

Como tal, essa técnica de coleta, que norteava a leitura dos textos, visava a constituição de certos acervos de frases, alguns conhecidos como hypomnemata, que em sua acepção

17 Soares (2007) ao discutir a problemática dos discursos acerca dos níveis de leitura dos brasileiros, manifestos nos enunciados "brasileiros leem pouco" e "brasileiros leem mal", esclarece que "[...] ler só é verbo intransitivo, sem complemento, enquanto seu referente forem as habilidades de decodificar palavras e frases", a partir do momento em que se ultrapassa esse nível básico de decodificação, "ler como prática social de interação com material escrito torna-se verbo transitivo, exige complemento" (SOARES, 2007, s/p).

18 Cf. Rosin (2016).

19 Cf. Medeiros e Curcino (2021). 
técnica "podiam ser livros de contabilidade, registros notariais, cadernos pessoais que serviam de agenda", anotações de citações, fragmentos de obras, "exemplos e ações de que se tinha sido testemunha ou cujo relato se tinha lido, reflexões ou debates que se tinha ouvido ou que tivessem vindo à memória" (FOUCAULT, 1992, p. 134).

Segundo o filósofo, os hypomnemata eram por excelência cadernos de anotações usados na Grécia antiga e que eram produzidos para que se pudesse realizar um exercício de leitura, de releitura e de meditação, etapas recomendadas como prática diária, tanto para auxílio da memória quanto para uso imediato em situações do cotidiano, de exercício público ou privado da fala, como técnica fundamental para a eloquência.

Apesar de estarem sempre "à mão" não se caracterizavam como diários íntimos, nem configuravam como um objeto contendo uma "narrativa de si mesmo":

Por mais pessoais que sejam, estes hypomnemata não devem, porém, ser entendidos como diários íntimos, ou como aqueles relatos de experiências espirituais (tentações, lutas, fracassos e vitórias) que poderão ser encontrados na literatura cristã ulterior. Não constituem uma "narrativa de si mesmo"; não têm por objetivo trazer à luz do dia as arcana conscientiae cuja confissão - oral ou escrita - possui valor de purificação. O movimento que visam efetuar é inverso desse: trata-se não de perseguir o indizível, não de relevar o que está oculto, mas, pelo contrário, de captar o já dito; reunir aquilo que se pôde ouvir ou ler, e isto com uma finalidade que não é nada menos que a constituição de si. (FOUCAULT, 1992, p. 137).

Entre os latinos, essa técnica e esse hábito ficaram conhecidos como apotegmas, ou seja, as máximas que consistem em frases estruturalmente breves, densas de significado moral e ético. Aristóteles (1979) caracteriza-as como uma forma de tradução, de "uma maneira de ver que não se refere a um caso particular", podendo ser aplicadas universalmente em discursos, restringindo seu uso às "pessoas de idade", uma vez que sua mobilização demandaria experiência em relação àquilo que se diz e tal experiência só poderia ser alcançada em decorrência da maturidade adquirida com o tempo.

A produção de conhecimento e sua validação, no período Helenístico, como pontua Curtius (1957), exigia a consulta e, consequentemente, o apoio em autores que eram tidos como algo além de uma "fonte de saber" e um "tesouro da ciência e da filosofia de vida", ou seja, que eram considerados como "autoridades científicas". Desse modo, as formas de produção do conhecimento se apoiavam no emprego de frases desses autores, tal como preconizado por Quintiliano. Ele as denominava de sentenças, devido à semelhança assertiva e formal com as decisões obtidas em assembleias públicas. Ao longo do tempo, o enfoque do uso dessas frases reside na preservação do latim e na mobilização de temas morais pelos poetas. 
Outros exemplos de uso dessa técnica, no mesmo período, eram chamados de exempla, que se assemelhavam, de certo modo, às sentenças em seu emprego. Quintiliano aconselha aos oradores que "tenha[m] à mão exemplos não só da história como também da mitologia e das lendas heróicas" (CURTIUS, 1957, p. 97), de modo que pudessem deles se valer sempre que necessário. Sua mobilização também se tornou requisito fundamental para a produção da poesia culta. Os exemplas podem ser encontrados "na poesia platônica do século XII [...] um cânon definitivo dessas figuras. Lá elas aparecem como arquétipos, que a sabedoria divina, agregou ao processo histórico" (CURTIUS, 1957, p. 97).

Portanto, apesar desses gêneros culturais (hypomnemata, máximas, exemplas) se valerem de procedimentos semelhantes de leitura que seleciona e coleta frases, de escrita que sistematiza e organiza em rubricas essas frases, registrando-as em suportes distintos, eles não se caracterizam do mesmo modo, seja em seu modo de composição, seja em seus usos finais.

\section{Da técnica na Idade Média: colher frases como se colhem flores}

Desde então, e ao longo de todo o período da Idade Média, são vários os exemplos do emprego dessas "frases" que são destacadas de textos originais e usadas com referência explícita ou não a sua origem na produção de outros textos. Essa técnica é mobilizada em diferentes gêneros e de diversas formas, seja com a finalidade didática para se ensinar técnicas de leitura e de escrita e formas adequadas de falar em público, seja para a reflexão filosófica de âmbito pessoal, seja, enfim, para a produção intelectual escrita e particularmente literária por parte de escritores, de poetas, de filósofos, de intelectuais, na longa Idade Média.

Embora essa tradição remonte à Antiguidade, a expansão do uso dessa técnica de seleção e coleção de frases dá-se nos períodos da Idade Média e Renascença, a partir principalmente do século XII - com o gênero conhecido por florilégios (coletâneas de frases) -, e posteriormente no século XVI, quando o destacamento de trechos de obras lidas para figurarem em cadernos de lugares-comuns, de uso particular, torna-se uma prática humanista e intelectual, sistematicamente difundida, empregada, ensinada e valorizada.

Os florilégios são compilações de frases de autores clássicos, conhecidos ordinariamente como "flores", cuja produção era restrita ao âmbito das coleções privadas no período medieval, passando posteriormente a figurar em domínio público. Essas citações no interior desse objeto eram organizadas de modo a manterem a ordem tal como apareciam nos textos-base. Elas eram também organizadas conjuntamente em uma classificação por autor selecionado, assim como por tema. Quando necessário, além dos enunciados selecionados versarem sobre a moralidade, acrescentavam-se-lhes breves e pontuais 
notas ou indicações relativas ao assunto abordado, comumente também de cunho moral. A ordem das frases, por autor, não era uma escolha feita ao acaso. Em vários florilegia, adotava-se a ordem crescente de dificuldade temática.

Ademais, os florilegia também se configuravam como um material de ensino para o latim (língua do saber). Diante do acesso escasso de informações, seja de textos antigos, seja dos próprios livros, eles se constituem como peças fundamentais na alimentação, e consequentemente, na elaboração de enciclopédias. Dentre os tesouros enciclopédicos da época, um dos exemplos de emprego dos florilegia para outras produções, datado da metade do século XIII, é o manuscrito enciclopédico Speculum maius de Vicent de Beauvais que reúne trechos de frases obtidas do Florilegium gallicum, sem menção a sua referência. Valendo-se dessas técnicas recorrentes na produção dos florilegia, Beauvais altera a ordem de aparição desses enunciados destacados em seus textos de origem. Produz ainda, outro manuscrito do mesmo tipo, intitulado Speculum morale, no qual apresenta uma concepção cristã da moral. Os títulos das seções são organizados sob a forma de perguntas, desenvolvendo nas seções uma descrição pormenorizada dos temas.

Assim como na Antiguidade, na Idade Média o emprego dessa técnica de leitura-seleção e de escrita-coleção atua como um dispositivo de memória, ou seja, um dispositivo técnico que contribui para a memorização desses fragmentos, para depreensão de seu valor e para seu uso sistemático em situações de fala e de escrita erudita, de reflexão filosófica para sua incorporação na vida, mas também como forma de preservação desses enunciados, ao longo do tempo.

\section{Na Renascença, a técnica humanista dos cadernos de lugares-comuns}

A partir do século XVI, conforme Cavallo e Chartier (s/d) e Chartier (1995), em pleno Renascimento, se destacam dois objetos que atestam, por sua própria existência, um modo de ler e de escrever que se vale do emprego dessa técnica de coleta e escrita de frases em cadernos, além de indiciarem práticas que em geral não se consideravam como próprias deste período: a "roda de livros" e os próprios "cadernos de lugares-comuns"20.

20 A "Roda de livros" foi concebida pelo engenheiro italiano Agostino Ramelli (1531-1600), em 1588. Ela consistia em um sistema que permitia a consulta simultânea de diversos livros, dispostos com as páginas abertas em uma estante-móvel, sob a forma de uma roda diante da qual o leitor-escritor, sentado em uma escrivaninha acoplada nessa roda, podia consultar diferentes livros enquanto fazia anotações. Já o "Caderno de lugares-comuns" equivalia a um caderno de notas, individual, para escrita e consulta, de fragmentos, de citações de textos de autores e obras anteriormente lidos e consultados, que eram organizados em rubricas temáticas, para facilitar a posterior utilização desses fragmentos, na escrita ou na declamação dessas frases. 
Esses dois objetos, por sua forma material, indiciam duas representações de práticas de leitura do período, o que leva a reconsiderar as divisões históricas e culturais que alguns estudiosos da história do livro e da leitura haviam assinalado entre: 1) práticas de leitura eruditas e aquelas populares, e 2) a passagem, no século XVIII, entre práticas de leitura intensivas para práticas extensivas.

No que diz respeito ao primeiro aspecto, Chartier (1995) relativiza essa divisão simplificada e polarizada entre leitores eruditos e leitores populares, segundo a qual estes se diferenciariam daqueles por empreenderem uma leitura mais "descontínua que desmembra os textos, descontextualiza as palavras e as frases, limita-se à literalidade do sentido" (CHARTIER, 1995, p. 189), tal como Carlo Ginzburg constatou em relação ao modo peculiar de leitura de Menocchio ${ }^{21}$. Se essa descrição é adequada para o caso de Menocchio, inspirados nela, a extensão dessas características a todos os leitores ditos "populares", do passado e do presente, precisa ser mais cuidadosa e prudente. Chartier (1995) nos lembra que leitores eruditos, neste mesmo período, também empreendiam um modo de ler descontínuo, fragmentado e fragmentador dos textos lidos, ou seja, a prática de leitura extensiva, tal como se pode constatar com a invenção da "roda de livros" e dos "cadernos de lugares-comuns", nos séculos XVI e XVII respectivamente. Logo, ler de modo fragmentado e fragmentando os textos lidos não era um atributo exclusivo de leitores populares, pouco familiarizados com as práticas intensivas de leitura atribuídas aos leitores eruditos.

Na segunda metade do século XVIII, historiadores ${ }^{22}$ afirmaram ter havido uma mudança significativa nas maneiras de ler, relativa à passagem de uma prática de leitura "intensiva", baseada no contato com "um corpus limitado e fechado de textos, lidos e relidos, memorizados e recitados, ouvidos e conhecidos de cor, transmitidos de geração em geração" (CHARTIER, 1999, p. 99), comumente exercida em relação à leitura de textos religiosos e sagrados, para uma prática de leitura "extensiva" que consistiria em um consumo mais amplo, variado e rápido de livros, devido à expansão da produção e distribuição do livro em sociedade e à laicização e variação de seu conteúdo. Esse modo extensivo de ler, a partir de então demandaria do leitor outra postura, diante de uma ampliação da circulação dos textos e uma ampliação dos títulos e dos gêneros então produzidos, que fomentaram, portanto, um modo de ler mais rápido, sem constantes retornos, de modo a viabilizar a leitura desse acervo cada vez mais amplo, disponível e variado de textos.

\section{Cf. Ginzburg (2006).}

22 Conforme constatado por Rolf Engelsing, em relação à história da leitura na Alemanha, e David Hall, na Inglaterra, ambos países protestantes, onde de fato essa divisão entre o modo de ler intensivo para o modo de ler extensivo foi mais marcado e a mudança histórica se deu efetivamente na segunda metade do século XVIII. Para o contexto francês, e de outros países europeus católicos, como nos esclarece Roger Chartier (1999 e 2005), isso não se deu da mesma forma, nem no mesmo período de maneira tão marcante. 
No entanto, considerando que as práticas de leitura e escrita não são simplesmente substituídas ou desaparecem ao longo da história, nem são exclusivas a um grupo social, o historiador nos lembra que os limites (temporais ou culturais) não são tão cerrados ou limítrofes, e que não é incomum defrontar-se com leitores "extensivos" em tempos de leitura prioritariamente "intensiva", nem com leitores "populares" que compartilham as mesmas práticas com leitores "eruditos".

Ambos objetos, a "roda de livros" e o "caderno de lugares comuns" testemunham que leitores de períodos anteriores ao século XVIII já empreendiam uma leitura de tipo extensiva, ou seja, familiarizada com a consulta a vários textos simultaneamente, de modo a ler, confrontar, comparar, anotar fragmentos de textos distintos que se lê e sobre os quais se faz anotações que permitem recuperar mais facilmente certas passagens, graças a sua transcrição e/ou indexação em um caderno, organizado por temas, segundo rubricas, que atua como um instrumento capaz de facilitar a lembrança e a localização de certas passagens de obras lidas ou consultadas, e contribuindo para a escrita de novos textos e para a argumentação oral de seus produtores.

Entre outras técnicas, essa prática humanista e erudita sinalizava, conforme o historiador, para uma certa "ansiedade das sociedades da primeira modernidade diante do excesso de livros e da desordem do discurso", que lhes exigia, portanto, a criação ou difusão de técnicas que permitissem controlar/organizar/hierarquizar esse excesso por meio, entre outras, da organização de antologias "[...] das obras mais importantes de um determinado gênero; [e a compilação de] coletâneas de trechos de livros segundo a técnica humanista dos lugares comuns; [...]" (CHARTIER, 2011, p. 33).

A ansiedade da perda, mas também do excesso, acompanha e responde às mudanças nas concepções da "escrita", da "obra" e sobretudo do "autor" e isso ao longo de toda a história da cultura escrita. Tal como observado por Chartier (2014), essas ansiedades são responsáveis tanto pela preocupação em se reunir e constituir, em sua sonhada totalidade e em uma desejada homogeneidade, a obra de um autor; como também pelo seu processo oposto, "de disseminar obras sob a forma de citações ou extratos" (CHARTIER, 2014, p. 33).

Se por um lado, notas, fragmentos e extratos são o ponto de partida para a construção de um texto, este se torna o ponto de partida para as notas, fragmentos e extratos que circularão, muitas vezes à revelia do conjunto do texto e da intenção de seu autor. Essa constatação ajuda a compreender como a cultura escrita tem sido "ampla e duravelmente construída com base em coletâneas de trechos, antologias de lugares-comuns (no sentido nobre dessa palavra na Renascença) e morceaux choisis [coletâneas]" (CHARTIER, 2014, p. 124), ou seja, da técnica de leitura e de escrita baseada na identificação, escolha, registro, coleção e uso de notas, de fragmentos de textos para a composição da totalidade de outros textos, orais ou escritos, dos mesmos gêneros daqueles de onde foram retiradas 
as frases ou em novos gêneros, alguns deles muito distantes formal e tematicamente dos primeiros.

\section{De volta ao presente: os repositórios de frases na internet}

Diferentemente do que imaginávamos acerca desse fenômeno atual de uso de "frases" destacadas ${ }^{23}$, disponíveis em repositórios na rede e empregadas em páginas de redes sociais diversas, por diferentes perfis de usuários da internet, ele não se trata de uma novidade contemporânea, oriunda e fomentada inusitadamente pelas tecnologias digitais disponíveis hoje. Observamos se tratar, antes, de um fenômeno cujas origens remontam à Antiguidade clássica e que, ao longo da história no Ocidente, assumiu formas e usos distintos, foi atualizado em práticas de escrita e de leitura também variadas na já longa história da cultura escrita ocidental.

Portanto, a técnica de leitura e de escrita, que concerne ao destacamento de frases de textos lidos para seu uso na produção de outros textos, além de antiga é também um procedimento comum e orientador dos modos de apropriação dos textos, que, na longa duração, ora foi reconhecida e validada como técnica fundamental e de domínio explícito, institucionalizado, e por isso ensinada como tal, como forma de ler bem os textos e de Ihes fazer a justa apreciação e homenagem, ora essa técnica foi estigmatizada e seu uso realizado de forma discreta, nem prioritária nem formalmente adotado ou ensinado, a não ser para situações muito específicas, segundo instituições e princípios bastante diversos desses que nortearam os usos na Antiguidade ou no Renascimento, o que foi inclusive viabilizado por técnicas e tecnologias de escrita e de leitura também singulares, se comparadas às que hoje em dia empregamos.

Essas formas de apropriação de fragmentos de textos lidos (ou mesmo de fragmentos de textos não necessariamente lidos por aquele que os emprega, mas disponíveis em função de sua seleção e disponibilização realizadas por outros), variam desde os modos e razões de sua coleta, passando pelos meios que os disponibilizam sob outra forma (em cadernos de notas, em livros publicados, ou em seus equivalentes digitais sob a forma de repositórios de frases), para que sejam empregados tanto em conversações do cotidiano ou mais formais quanto na escrita de outros textos, eventualmente de diferentes gêneros e com diferentes finalidades do que aquelas dos textos de onde esses fragmentos, muitas vezes sob a forma de frases, foram retirados.

Uma das razões que persiste, apesar das mudanças no tempo e no espaço que caracterizam os diferentes usos dessa técnica, tem a ver com a importância do renome de

23 Cf. Krieg-Planque (2011) e Maingueneau (2014), entre outros, que se dedicaram a descrever o funcionamento discursivo de frases destacadas, especialmente aquelas empregadas na contemporaneidade, em textos midiáticos e políticos. 
alguns autores e do prestígio adquirido por certas obras, e que por isso são considerados fontes fundamentais, referências incontornáveis do que em geral se pode e se deve citar, mesmo quando o objetivo é a sua crítica, mesmo quando a razão é para demarcar certa distância, deles se afastar, ou estabelecer, enfim, uma diferença de posição. Além disso, ainda que eventualmente se possa recolher, colecionar e citar frases de textos e autores que não se conhece, isso não significa que não sejam textos e autores reconhecidos socioculturalmente, e sobre os quais se pressupõe o valor do que enunciam, logo, alguns dos que se apropriam desses fragmentos sabem, sem necessariamente ler e conhecer certos textos e autores, que as frases a eles atribuídas têm um valor distintivo, gozam de reconhecimento cultural e podem conferir sentidos na produção de outros textos, na referência a esses fragmentos. É com base no conhecimento prévio, compartilhado e consensual dessa "mais-valia" simbólica que parte dos usos desses fragmentos se explica hoje.

\section{Algumas considerações}

Buscando reconstituir fragmentos da história da "arte do fragmento" de que nós somos hoje herdeiros, passeamos em saltos por alguns tempos e sociedades, em que a leituraseleção e a escrita-coleção gozaram ora de prestígio, ora de rebaixamento, sendo em um tempo ensinadas em detalhe, em outro realizadas de forma espontânea, ao acaso, de forma assistemática, sem método. Nesse retorno, não trabalhamos com equivalentes dessas frases e de seus usos relativamente "populares" da atualidade.

Uma das primeiras impressões que tivemos, ao compararmos genericamente essa "cultura do fragmento" em sua história, partindo da multiplicação das frases destacadas, das "frases sem-texto"24 que pululam nas redes sociais hoje em dia, é a do caráter paradoxal dessa dupla existência dos objetos culturais produzidos por essa lógica da seleção, da fragmentação, da coleção de frases, no mundo da cultura escrita antes e depois da digitalização dos textos.

24 Maingueneau (2014) tem se dedicado particularmente ao estudo desse fenômeno. Ele o define como processo de aforização, que consiste, segundo ele, no destacamento de uma frase de um texto, que se autonomiza semanticamente dele sob a forma específica de aforisma, ou seja, de "uma frase com ar sentencioso, que resume em algumas palavras uma verdade fundamental" (MAINGUENEAU, 2014, p. 27). Essas frases compreendem, portanto, uma verdade repetível, aquilo que é da ordem do que deve ser memorável, e por consequência, memorizável. Ademais, as aforizações correspondem a um conjunto de frases sem texto, que podem ser subdivididas em primárias - provérbios, adágios, divisas e slogans -, que não demandam a consulta de seu texto de origem para seu entendimento e secundárias - enunciados destacados de textos que estabelecem uma dependência do contexto-fonte para sua recepção. É do tipo de aforização secundária aquelas que prioritariamente encontramos no corpus desta pesquisa. 
Um dos paradoxos que as novas tecnologias digitais de formulação e circulação dos textos nos apresentam, quanto às formas de escrita e de leitura dos textos da atualidade, é exatamente o da possibilidade de ampliação da produção de textos, de sua circulação, da visibilidade que as práticas de leitura dos leitores comuns adquire, mas também o risco da perda pela dispersão exponencial desses escritos, pela multiplicação desses objetos culturais contemporâneos virtuais, derivados dessa cultura do fragmento, instantâneos e muito frágeis do ponto de vista de suas possibilidades de conservação e duração histórica, seja por serem considerados gêneros menores, seja por serem produzidos massivamente e se perderem muito rapidamente na proliferação contínua de textos dessa fábrica de novidades que se tornou a internet.

Um exemplo bastante contemporâneo desse tipo de produção vinculada à cultura do fragmento é, sem dúvida, o meme. Os memes repetem, reproduzem, fazem proliferar outros textos, mas não de qualquer modo: eles reatualizam, uma vez mais, a arte do destacamento e da citação, a arte do fragmento e de sua proliferação ${ }^{25}$. Encontram público amplo entre os jovens conhecidos hoje como nativos digitais. Os memes, hoje, assim como as "mensagens compartilhadas" e as "mensagens em PowerPoint", ontem, e outros tantos tipos de textos que a eles se assemelham em seus princípios de produção e circulação, nos modos como interpelam os leitores e produtores de textos atuais, ecoando lembranças longínquas de práticas antigas e duradouras, exigem nossa atenção, exigem uma análise discursiva e histórica de seus antecedentes, do que de nossa cultura escrita atual, afetada incisivamente pela revolução eletrônica, tem de continuidade, mas também de rompimento e irrupção de um novo acontecimento.

\section{REFERÊNCIAS}

ABREU, M. Diferentes formas de ler. 2001. Disponível em: http://www.unicamp.br/iel/ memoria/Ensaios/Marcia/marcia.htm. Acesso em: 09 ago. 2013.

ARISTÓTELES. Arte retórica e arte poética. Rio de Janeiro: Edições Ediouro, 1979.

CAVALLO, G.; CHARTIER, R. Les modèles de lecture des temps modernes. In: BNF Classes: le site pédagogique de la Bibliotèque National de France. Seção: L'aventure du livre. (s/d). Disponível em: http://classes.bnf.fr/livre/arret/auteur-lecteur/lecture/06.htm. Acesso em: 10 jul. 2019.

CHARTIER, R. "Cultura Popular": revisitando um conceito historiográfico. Revista Estudos Históricos, Rio de Janeiro, Fundação Getúlio Vargas, v. 8, n. 16, p. 179-180, 1995.

25 Cf. a esse respeito Silva e Curcino (2021). 
CHARTIER, R. A ordem dos livros: leitores, autores e bibliotecas na Europa entre os séculos XIV e XVIII. Brasília: Editora da Universidade de Brasília, 1999.

CHARTIER, R. Os desafios da escrita. São Paulo: Editora da UNESP, 2002.

CHARTIER, R. Leituras e leitores populares: a Bibliotèque bleue e a literatura de colportage. Revista Desenredo, v. 1, n. 1, p. 104-119, jan./jun. 2005. Disponível em: http:// seer.upf.br/index.php/rd/article/view/480. Acesso em: 12 jul. 2020.

CHARTIER, R. Uma trajetória intelectual: livros, leituras, literaturas. In: ROCHA, J. C. de C. (org.). Roger Chartier - A força das representações: história e ficção. Chapecó: Argos, 2011. p. 21-54.

CHARTIER, R. A mão do autor e a mente do editor. São Paulo: Editora UNESP, 2014.

CHIARI, G.; SARGENTINI, V. Mentirosos, corruptos e comunistas! As Fake News e o politicamente incorreto. Discurso \& Sociedad, Barcelona, v. 13, n. 3, p. 449-467, 2019. Disponível em: http://www.dissoc.org/ediciones/v13n03/ DS13\%283\%290liveiraSargentini\&Chiari.pdf. Acesso em: 10 jul. 2020.

CURCINO, L. Práticas de leitura contemporâneas: representações discursivas do leitor inscritas na revista Veja. 2006. Tese (Doutorado em Linguística e Língua Portuguesa) - Faculdade de Ciências e Letras, Universidade Estadual Paulista "Júlio de Mesquita Filho", Araraquara, São Paulo, 2006.

CURCINO, L. Mutações do suporte e dos gêneros discursivos: indícios de mudanças da leitura e dos leitores? In: AGUIAR, V. T.; CECCANTINI, J. L. (org.). Teclas e dígitos: leitura, literatura \& mercado. São Paulo: Cultura Acadêmica, 2010. p. 13-23.

CURCINO, L. Princípios de não homologia entre o verbo e a imagem: breve análise de uma estratégia de escrita da mídia. Estudos Linguísticos, São Paulo, n. 40, v. 3, p. 13981407, set./dez. 2011.

CURCINO, L. Suporte e sentido: questões de leitura e análise do discurso. In: GREGOLIN, M. R. V.; KOGAWA, J. M. (org.). Análise do discurso e semiologia: problematizações contemporâneas. Araraquara: Laboratório Editorial/São Paulo: Cultura Acadêmica, 2012. p. 189-205. 
CURCINO, L. Desafios ao ensino de leitura frente às ordens que regulam sua produção na atualidade. In: MOMESSO, M. R. et al. (org.). Das práticas do ler e escrever: ao universo das linguagens, códigos e tecnologias. Porto Alegre: CirKula, 2014. p. 45-62.

CURCINO, L. Conhecereis a verdade e a verdade vos libertará: livros na eleição presidencial de Bolsonaro. Discurso \& Sociedad, Barcelona, v. 13, n. 3, p. 468-494, 2019. Disponível em: http://www. dissoc.org/ediciones/v13n03/DS13\%283\%29Curcino.pdf. Acesso em: 10 jul. 2021.

CURCINO, L. Lives e livros: versículos e verdade na eleição presidencial brasileira. In: CURCINO, L.; SARGENTINI, V.; PIOVEZANI, C. (org.). Discurso e (pós)verdade. São Paulo: Editora Parábola, 2021.

CURTIUS, E. R. Sentenças e Exempla. In: CURTIUS, E. R. Literatura Europeia e Idade Média Latina. São Paulo: Editora da Universidade de São Paulo, 1957.

EISENSTEIN, E. L. A revolução da cultura impressa: os primórdios da Europa Moderna. São Paulo: Ática, 1998.

FOUCAULT, M. O que é um autor? Lisboa: Vega, 1992.

FOUCAULT, M. A arqueologia do saber. Rio de Janeiro: Forense Universitária, 2014.

GINZBURG, C. O queijo e os vermes: o cotidiano e as ideias de um moleiro perseguido pela Inquisição. São Paulo: Companhia das Letras, 2006.

MAN, J. A revolução de Gutenberg: a história de um gênio e da invenção que mudaram o mundo. Rio de Janeiro: Ediouro, 2004.

MAINGUENEAU, D. A fala sentenciosa. In: MAINGUENEAU, D. Frases sem texto. São Paulo: Parábola Editorial, 2014.

MEDEIROS, R. R. A.; CURCINO, L. Ler em voz alta: práticas de ensino no secundário e a formação cultural das elites brasileiras no século XX. Working Papers em Linguística. Florianópolis, v. 21, n. 3, 2021. Disponível em: https://periodicos.ufsc.br/index.php/ workingpapers/article/view/71360. Acesso em: 25 nov. 2021.

MOSS, A. Les recueils de lieux communs: apprendre à penser à la Renaissance. Genève: Droz, 1993. 
ROSIN, P. Peculiaridades do exercício da função autor em redes sociais: uma análise discursiva de "mensagens compartilhadas" pelo Facebook. 2016. Dissertação (Mestrado em Linguística) - Centro de Educação e Ciências Humanas, Universidade Federal de São Carlos, São Carlos, 2016. Disponível em: https://repositorio.ufscar.br/ handle/ufscar/9064. Acesso em: 10 jul. 2020.

ROSIN, P.; CURCINO, L. Peculiaridades do exercício da função autor: uma análise discursiva de "mensagens compartilhadas" no Facebook. Revista Estudos Linguísticos, São Paulo, v. 44, n. 3, p. 1155-1167, set./dez. 2015. Disponível em: https://revistas.gel. org.br/estudos-linguisticos/article/view/1046/648. Acesso em: 10 jul. 2021.

SAENGER, P. A leitura nos séculos finais da Idade Média. In: CAVALLO, G.; CHARTIER, R. (org.). História da leitura no mundo ocidental. v. 1. São Paulo: Editora Ática, 1998. p. 147-184.

SARGENTINI, V.; CARVALHO, P. H. V. A vontade de verdade no discurso: os contornos das fake news. In: CURCINO, L.; SARGENTINI, V.; PIOVEZANI, C. Discurso e (pós)verdade. São Paulo: Parábola, 2021.

SILVA, R. S. Controle remoto de papel: o efeito do zapping no jornalismo impresso diário. São Paulo: Annablume/FAPESP, 2007.

SILVA, J.; CURCINO, L. Memes sobre a leitura: uma análise discursiva do princípio da destacabilidade de seus enunciados verbais e imagéticos. In: CUTRIM, I. G.; CRUZ, M.; FARIA, M. G. S. Práticas Discursivas em espaço digital: múltiplos recursos. São Luís: EdUFMA, 2021. Disponível em: https://ebook.shcomunicacao.com.br/2021/03/24/ praticas-discursivas-em-espaco-digital-multiplos-percursos/. Acesso em: 10 jul. 2021.

SOARES, M. B. Ler, verbo intransitivo. 2007. Disponível em: http://tudosobreleitura. blogspot.com/2011/07/ler-verbo-transitivo.html. Acesso em: 10 mar. 2019. 